\title{
A Dissemination Strategy to Enhance National Identity in Hong Kong
}

\author{
Qingxiang Feng ${ }^{1}$ \\ ${ }^{1}$ Institute of Guangdong Hong Kong and Macao Development Studies, Sun Yat-sen University, Guangzhou, \\ China
}

Correspondence: Qingxiang Feng, Institute of Guangdong Hong Kong and Macao Development Studies, Sun Yat-sen University, Guangzhou, 510275, China. E-mail: fengqx8@mail.sysu.edu.cn

Received: April 12, $2020 \quad$ Accepted: May 23, $2020 \quad$ Online Published: May 31, 2020

doi:10.5539/ass.v16n6p37

URL: https://doi.org/10.5539/ass.v16n6p37

\begin{abstract}
As an important issue in the theory and practice of "one country, two systems", the national identity in Hong Kong has been given a lot of attention as some deep-seated problems accumulated over a long period of time in Hong Kong have become increasingly acute in recent years. From the perspective of social communication, modern media and public opinion are important factors affecting the strength of national identity in Hong Kong. In view of this, in order to enhance the national identity in Hong Kong, it is necessary to cultivate patriotic and Hong Kong-loving media and improve the social communication platform of national identity, so as to occupy the leading edge of public opinion, cope with the erosion of the wrong trend of thought, spread the national image of China and demonstrate the national confidence of China.
\end{abstract}

Keywords: Hong Kong Special Administrative Region, national identity, modern media, public opinion, national image

\section{Introduction}

In contemporary Hong Kong, the values are diverse, the culture is mixed, the mind is open, and public opinion is free, there is no mainstream media in the true sense, and no official institution to manage and guide the culture. Patriotism, as a basic civic morality and emotional attitude, has been frequently deconstructed and reconstructed by local media in Hong Kong. The fragmented national view has been smeared with a thick layer of ideological color, becoming a new material for some Hong Kong media to grandstand and attract attention, and it has even been used by some populists as an object of emotional input and output to cater to the atmosphere of social politicization. In the face of such circumstances, it is necessary to improve the dissemination system of national identity in Hong Kong, create a favorable public opinion atmosphere and external conditions to break the dilemma of national identity of Hong Kong residents, and enhance the sense of belonging, identity and pride of Hong Kong people towards the country.

\section{Literature Review}

Since the 1970s, with the impact of globalization on nation-states, the crisis of identity has spread from the confusion of individual minds to the torture of national identity, and the focus of identity research has been shifted from psychology and philosophy to political science. National identity has gradually become a hot topic in foreign academic circles. Anderson (2011) believes that whether the subject agrees with the nation-state to which he belongs depends largely on his subjective political imagination. In his view, the imagination of political community is not the fabrication of "false consciousness", but the result of the convergence, extraction and refinement of various historical forces. Facing the challenge of cultural pluralism, Huntington (2005) put forward the question about identity of "who we are". He believes that the national identity of the United States is to identify with the fundamental characteristics of "Anglo-Protestant Culture" and to revive the "unified" citizenship of the United States. In a word, national identity is to integrate the differences of ethnic groups, values and beliefs through a common culture, based on civic responsibility and patriotic feelings (Giroux, 1994).

In Chinese academic circles, the research objects of national identity include not only different regions, nationalities and groups, but also different countries. First, on the national identity of China's Hong Kong, Macao and Taiwan regions. Chen Wei (2017) suggested to dissolve the tension between Hong Kong society and the central government, create a positive national image and to enhance patriotism through the spread of national consciousness and media construction under social interaction; Lu Pinghui (2009) proposed measures to 
strengthen Macao's national identity from three aspects: economic development, democratic political construction and civic education; Liu Hong (2013) studied the influence of Taiwan's national identity on cross-straits relations and put forward suggestions to promote the "one China" identity. Second, on national identity of China's ethnic minorities and student groups. Huang Yan (2011) believes that the rise of ethnic identity to national identity is not only the political trend and path of national development, but also the key to national development; Chen Dayun (2010), taking minority college students as research objects, proposed strategies to cultivate their national identity consciousness from three levels: the state, the society and the school. Third, on national identity of other countries. Liu Ying (2016) interpreted the trajectory of Russian reconstruction of national identity from the two dimensions of traditional historical culture and authoritarian system; Fan Weiwei (2011) explored the historical evolution of Canadian national identity from fragility, ambiguity, change, chaos to reconstruction in the context of multiculturalism, with citizenship education as the starting point; Li Zhidong examined the historical vein and construction path of Singapore's national identity from multiple dimensions. It can be seen that the existing studies on national identity in the academic circle have formed a situation in which multiple disciplines and multiple perspectives compete with each other, providing an important analytical framework and theoretical enlightenment for this study.

\section{Point of View}

\subsection{Cultivating Patriotic and Hong Kong-loving Media and Improving the Social Dissemination Platform of National Identity}

Patriotic and Hong Kong-loving media workers are the subjects of the dissemination of national ideology, the interpretation of national philosophy and the diffusion of Hong Kong values. As the issuer of media information, the subjective initiative of patriotic and Hong Kong-loving media workers often directly affect the rational cognition and objective judgment of the public in Hong Kong toward national will, policy and strategy. Patriotic and Hong Kong-loving media are not only a mirror reflecting the social reality of Hong Kong, but also the organizations carrying the mission of disseminating national identity, determining the depth and breadth of the public's understanding of the country in Hong Kong to some extent.

3.1.1 Improving the Survival and Development Conditions of Patriotic and Hong Kong-loving Media, Ensuring Talent Supply for the Dissemination of National Identity in Hong Kong

The media ecology in contemporary Hong Kong is liberal-oriented, and the market competition is extremely fierce. The politically oriented patriotic and Hong Kong-loving media are often squeezed by popular and sensational media and elite commercial media. As a result, they are in a relatively weak position in the social media system of Hong Kong. Patriotic and Hong Kong-loving media workers generally have good education background, professional media literacy and stronger patriotism, but their overall treatment is not ideal, and their pro-china and pro-government political stance is often attacked or ostracized by social democrats and their supporters. Thus these workers' social status is embarrassed, and their career mobility is high. To promote the construction of national identity in Hong Kong, we need to cultivate more patriotic and Hong Kong-loving media personnel, and require more young talents who acknowledge the ruling philosophy of the Chinese Communist Party (CCP) to join the patriotic and Hong Kong-loving publicity team. To that end, we must pay attention to the development situation of this professional group, provide them with necessary financial support, suitable working environment, reasonable promotion space and promising political career prospects, and establish a dedicated association of patriotic and Hong Kong-loving media workers to offer them with opportunities for further study, interview work collaboration mechanism and humanized service of daily life.

3.1.2 Improving the Internal Operation System of Patriotic and Hong Kong-loving Media, Constructing an Information Platform to Introduce China and CCP Objectively

The coordinated operation of the organizational structure, rules and regulations, editorial team, and platform construction of the patriotic and Hong Kong-loving media directly determines the timeliness and quality of the dissemination of national identity in Hong Kong. To realize these systematic goals, we need to enhance the national consciousness, professional quality, innovation ability and global vision of patriotic and Hong Kong-loving media workers, and let them respect the truth, stick to the bottom line of social justice, use the dynamic information collection system scientifically, follow the pulse and direction of the mainstream public opinion in Hong Kong, build an elaborate news reporting framework objectively and comprehensively, integrate the macro meaning and micro text into each other, and participate in the whole process of interpretation and dissemination of the will of the state. We also need to pay attention to the online social media interaction and the offline patriotic and Hong Kong-loving alliances, improve the dissemination efficiency and feedback speed, and realize the close combination of information absorption and information integration. Through the optimization of 
various links in the media internal system, we can output credible, insightful and attractive national information interpretation and world development situation analysis, promote the sublimation of perceptual understanding of China to rational evaluation of China, and provide an information platform for Hong Kong people to understand the motherland and the party in an all-round, multi-level and wide-ranging way.

3.1.3 Handling the External Relations and Self-censorship of Patriotic and Hong Kong-loving Media, Providing an Appropriate Environment for National Identity

The basic positioning of patriotic and Hong Kong-loving media is the dissemination carrier of national ideology and the public opinion megaphone of Hong Kong's social reality, and its comprehensive performance cannot be achieved without the influence of political and social environment. Under the principle of "one country, two systems", Hong Kong is a society where values are diverse, the press is free, different voices can find a way to express themselves and different emotions can find an outlet. The media ecology of Hong Kong is always invisibly intertwined with the hand of power and the hand of the market which are resulting from the multiple pressures of politics de-authorization and market fundamentalism, making the patriotic and Hong Kong-loving media inevitably face the dilemma of choosing "faith or bread". In view of this, constructing a reasonable and effective compensation and incentive mechanism is a relatively effective solution, which can balance the choice of patriotic and Hong Kong-loving media between national interests and commercial interests, properly handle the relationship between their deep involvement in the political wrestling field and their relatively independent critical remarks, and give full play to their role as a bridge of communication, exchange and identity among the central government, the SAR government, the establishment parties and Hong Kong citizens, so as to form a benign mechanism of mutual restriction, evaluation and supervision between political organizations, media organizations and the public. In this way, patriotic and Hong Kong-loving media can play a full role in spreading national identity.

\subsection{Occupying the Leading Edge of Public Opinion and Coping with the Erosion of Wrong Trend of Thoughts}

How to strengthen national identity is like a test paper handed to Hong Kong society by the central government. This process often requires the support of public opinion, which ultimately comes from the collision of thoughts, the clash of values and the conduction of public emotions. When the top-down mobilization of political elites in a society is interwoven with the appeals of the public from the bottom up, public opinion is likely to form a series of chain reactions such as fragmentation, stratification, or cohesion. To promote the national identity of Hong Kong residents in the competitive arena of different social trends, it is inevitable to face the competition of different groups for information discourse and the control of meaning symbols.

3.2.1 Enhancing the Hardware and Software Capabilities of Disseminators, Occupying the Leading Edge of Public Opinion

The battle for public opinion reflects the strength of various social forces in occupying resources, power, ideas and public opinions by means of mass media. As a Chinese saying goes, "to forge iron, you need a strong hammer", the Hong Kong SAR government should further increase the allocation of resources to the construction of the official information release platform, enhance official spokesmen's discourse interpretation ability, value radiating ability and interpersonal influence ability, and strengthen the communication and cooperation with the patriotic and Hong Kong-loving media, so as to jointly play the role of "KOL". When it comes to conflicts of public opinion concerning major issues such as state interests, constitutional order and political principles, it needs to expand channels to provide media literacy education, and improve the ability of Hong Kong people to distinguish false and true mass media information, to think independently and to judge the value correctly. The government also needs to change the traditional ideas of laissez-faire or passive anti-blocking public opinion governance to the dissemination strategy of active persuasion, occupation and correction, so as to provide the public of Hong Kong with a weighty meter for judging domestic public events, and compress as much public opinion space as possible of the unhealthy trends and heretical ideas. On the operational level, it shall integrate Internet text information recognition, extraction and tracking technology and artificial intelligence system, and develop an automated public opinion analysis engine, so as to capture Hong Kong's emotional response, political attitude and ideological tendency to domestic hot events, focal issues and changes accurately and timely; the emerging media technologies can be used to arm and expand the ways of the publicity of patriotic and Hong Kong-loving theme, such as multidimensional plane display, virtual reality technology, and APP, so as to introduce the patriotism space-time experience for Hong Kong people from aspects of vision, hearing, and touch, create more virtual presence and a sense of participation, narrow the spiritual distance between Hong Kong people and the country, and expand the group of patriotic Hong Kong people. In terms of popularization form, we can draw on the Singapore government's official propaganda appropriately, to 
broadcast lectures, seminars and meetings on We-Media (such as Facebook, WhatsApp commonly used by Hong Kong people), and finely divide the discussion focus of national development issues. In this way, we can absorb more patriotic and Hong Kong-loving populace orderly into the rational discussion of the "one country, two systems" and the development of political system, and attract more Hong Kong youth to participate into the national strategic development plan and the Hong Kong's development blueprint drawing, making it a hot topic, life topic and personal topic leading the public opinion in Hong Kong.

3.2.2 Actively Dealing With the Erosion of National Identity by the Wrong Trend of Thoughts in Hong Kong and the West

Marx (1995) pointed out that "if viewed from the perspective of concept, the disintegration of a certain form of consciousness is enough to bring about the end of the whole era." It can be seen that the change of ideology and the surge of social ideological trend can have a significant impact on the stability and development of a society, especially the diffusion and erosion of the wrong and negative social ideological trends, which should be prevented and checked at the outset. For the historical nihilism, radical nativism and separatism in Hong Kong, the political, academic and media circles need to take the initiative to respond and provide countermeasures. For example, the government should allocate resources to support experts, think-tanks and young scholars in the field of humanities and society to carry out academic analysis and empirical evaluation of these social trends that threaten national security and challenge national political order, so as to provide decision-making basis for the public opinion governance of the Hong Kong SAR government; based on the overall judgment of the changing trend of public opinion, the Hong Kong SAR government should establish the corresponding early warning, prevention, control and correction mechanism for those social ideological trends against the central government, so as to block the unstable ideological factors when they are still in the embryonic stage of practice transformation; patriotic and Hong Kong-loving media can cooperate with the government to promote the socialization, symbolization and microcosm expression of the will of the state in Hong Kong, and guide the local social trends in Hong Kong to follow the direction of economic and social development, so as to avoid the irrational and populist turn. Regarding some media such as the "Undergrad" and "Apple Daily" containing language violence and position bias of anti-China and anti-communist, as well as the deconstruction and impact of western social trends like neo-liberalism, post-modernism, and anarchism on the national values of Hong Kong people, the Hong Kong SAR government and the patriotic and Hong Kong-loving media need to keep an awake cognition and judgment, to keep leading initiative, criticize and dissolve the realistic destructiveness behind these social thoughts, and take a stand and make a mainstream voice. At the same time, the government should actively assist the central government, in the proper use of diplomatic means, to cut off the inextricably linked interests relationship between western countries such as Britain and the United States and the forces aiming to separate China, and to boycott those media personnel who openly support "Hong Kong independence" and secretly accept political contributions from the west.

\subsection{Spreading the National Image of China and Demonstrating the National Confidence of China}

The national image of China is the subjective projection of China's objective form in people's cognition system, reflecting the overall impression, evaluation and feeling of the public towards the country. It generally includes domestic and international levels, and positive and negative aspects. The symbolic, visual and meaningful dissemination and translation system of the media provides a realistic condition for the establishment and output of the national image. It is an effective way to enhance the national identity in Hong Kong by using the power of media to shape China's national image, maintain the national mainstream value, and demonstrate the national confidence.

\subsubsection{Using Modern Media to Present China's National Image on the International Stage of Hong Kong}

The dissemination of national image is a comprehensive process of conveying national development strategy and national interest game, providing symbolic and legal resources needed for the exercise of national sovereignty. What kind of national image to show, how to effectively use the media mouthpiece to publicize the national image, all these issues involve the interests of the state, and need the government to carry out appropriate intervention, clever design, interest balance and promotion guidance. This also indicates that the government's public responsibility and media's social responsibility are tied together. Throughout the world the national image dissemination experience, the construction of national image inevitably involves the embedding of political ideology and the grafting of cultural psychological structure. It is a common construction technique to give priority to the positive publicity of oneself and to criticize the negative events of others. In the media environment of "one country, two systems", the central government can draw on the dissemination experience of developed countries appropriately, use the force of a state and combine marketization operation and modern 
media, to tell a good Chinese story, spread the voice of China, and display an authentic, three-dimensional, and comprehensive China to the world through Hong Kong, the international showcase for the western world to understand China $(\mathrm{Xi}, 2016)$. Meanwhile, the dissemination of national image is a process of dynamic construction, interaction and mutual influence, and the feelings, evaluation and feedback of the international community towards China will also react on the understanding and judgment of Hong Kong people towards their own country. Some imaginations about China in the framework of western centrism tend to reverse the positions of the host and the guest and magnify the negative images of China such as "hegemony, autocracy and backwardness". Their wishful thinking holds that the rapid growth of China is bound to be difficult to overcome the "Thucydides's trap" in international relations (Shen, 2015). Although these statements are the lousy cliches of some foreign media, they do disturb the original impression on the country of Hong Kong people. In this regard, the state media should take the initiative to strengthen the function of Ideological State Apparatuses, increase the opportunities for interaction and dialogue with Hong Kong people, and do a good job in explaining facts, communicating ideas and exchanging values. It should be noted that whether a good national image can leave a deep impression on the hearts of Hong Kong people often depends on the positive effects of equal, in-depth and constant interaction between subjects on media platforms.

3.2.2 Using Modern Media to Integrate the Identity of China's National Image into the Daily Life of Hong Kong People

The dissemination of national image cannot only rely on media elites' standardized, visualized and meaningful presentation of the value of national identity, but also must be deep into the social life of the public, so as to transform the national image and its national ideological information into the personal experience, resonant memory, pleasant emotions and daily things of the ordinary people. The concept of the country of ordinary people is gradually formed in the process of drinking tea and chatting pleasantly, sitting on their couch, with the help of modern media (Liu, 2009). Therefore, the state media can make use of the positive meaning and visual symbol generated by the theme micro-video, public service advertising, electronic publication, and patriotic effect of Hong Kong and Macao stars, to shape the national image of China, and improve the exposure and penetration of national symbols in Hong Kong people's working environment and family life, by means of embedded construction. For instance, the central propaganda department releases the national image promotion video on the commercial wall of Hong Kong through the government's Purchase of Service Contracting, or the national press and publication institutions develop in-depth business cooperation with Hong Kong publishing industry, to promote books, audio and video products, and documentaries with extensive influence in the Chinese mainland, such as Xi Jinping: The Governance of China, Ninety Years of the Chinese Communist Party, and Amazing China, to enter the book exhibition and retail market of Hong Kong. There are two highlights of this kind of national image dissemination path: first, it provides objective material for Hong Kong people to imagine China and unlock the mysteries of CCP, and can eliminate subtly the social psychology of "rejecting the communist party" and the collective memory of "asylum-seekers" left over by some Hong Kong people in a particular historical period in the last century, and enhance Hong Kong people's understanding of the country and the mutual trust between each other, to make their subjective evaluation of the country interrelated with the psychological needs of self-identification and self-esteem; second, it places the social defense psychological mechanism into the national image construction, in light with the micro-life scenes of Hong Kong people. In this way, even in the face of the impact of the negative perception of the country, such as the demonization of China by some foreign media, Hong Kong people are also able to manage their emotions calmly and rationally, and find reference standards from their familiar life experience to carry out psychological repair on national identity anxiety consciously.

\section{Conclusions}

Strengthening national identity in Hong Kong is not only an important task for the central government to govern Hong Kong, but also an important part of the theory and practice of "one country, two systems". In the context of the new era, modern media and public opinion have become important factors affecting the change of national identity in Hong Kong. Social public opinion comes from the collision of ideas, the confrontation of values and the conduction of group emotions, which often influences the public's perception and evaluation of the country through modern media and other carriers. Therefore, in order to enhance the national identity in Hong Kong, it is necessary to cultivate patriotic and Hong Kong-loving media workers and improve the social dissemination platform of national identity, so as to occupy the leading edge of public opinion, cope with the erosion of wrong trend of thoughts, spread the national image of China and demonstrate the national confidence of China. 


\section{Acknowledgement}

This research was financially supported by China Postdoctoral Science Foundation (No.2019M663356) \& Sun Yat-sen University's Special Funds for Basic Scientific Research Expenses (No.20wkpy85).

\section{References}

Benedict, A. (2011). Imagined Communities: Reflections on the Origin and Spread of Nationalism (pp. 1-8). Translated by Wu Ruiren, Shanghai: Shanghai Renmin Publishing House.

Chen, D. Y., Wu K. S., \& et al. (2010). Research on the Innovation of National Identity Education for Minority University Students (pp. 154-223). Beijing: The Ethnic Publishing House.

Chen, W. (2017). Media Construction of Identity in Hong Kong: From the Perspective of Social Constructivism. Hong Kong and Macao Journal, 1, 86-92.

Fan, W. W. (2011). National Identity in a Multicultural Society: A Study on Canadian Citizenship Education Since 1970s (pp. 58-136). Changchun: Doctoral Dissertation of Northeast Normal University.

Giroux, H. A. (1994). National Identity and the New Nationalism: The Rise of Ethnic Absolutism in the United States. International Journal of Educational Reform, 3(3), 38-42.

Huang, Y. (2011). National Identity--The Goal Construction of National Development Politics (pp. 169-207). Beijing: The Ethnic Publishing House.

Karl, M., \& Friedrich, E. (1995). Karl Marx Frederick Engels Collected Works (Vol. 30, p. 539). Beijing: People's Publishing House.

Li, Z. D. (2013). Research on National Identity of Singapore (1965-2000) (pp. 41-93). Beijing: China Renmin University Press.

Liu, G. Q. (2009). Reconstruction of Media Identity: A Study on Global Dissemination and the Construction of National Identity (p. 99). Chengdu: Sichuan University Press.

Liu, H. (2013). An Introduction to “National Identity” in Taiwan (pp. 222-291). Beijing: Jiuzhou Press.

Liu, Y. (2016). The Construction of National Identity of Russia and Its Enlightening Meaning for China. Journal of Peking University (Philosophy and Social Sciences), 3, 123-131.

Lu, P. H. (2009). On the Construction of National Identity and Ethnic Identity in Macao SAR. Study \& Exploration, 6, 69-74.

Samuel, H. (2005). Who Are We? The Challenges to America's National Identity (pp. 33-118). Translated by Cheng Kexiong, Beijing: Xinhua Publishing House.

Shen, M. Z. (2015). How Can Great Powers Avoid the “Thucydides's Trap”?. People's Daily (Overseas Edition), 11-27(16).

Xi, J. P. (2016). A Series of Important Speeches by General Secretary Xi Jinping (p. 209). Beijing: Xuexi Press, People's Publishing House.

\section{Copyrights}

Copyright for this article is retained by the author(s), with first publication rights granted to the journal.

This is an open-access article distributed under the terms and conditions of the Creative Commons Attribution license (http://creativecommons.org/licenses/by/4.0/). 